\title{
LOCUS OF CONTROL, DEPPRESSIVE SYMPTOMS AND PERCEIVED ACADEMIC ACHIEVEMENT OF LEARNERS: A SYSTEMIC REVIEW
}

VIRGINIA NNENNA MADU

(Received 25, January 2018; Revision Accepted 6, April 2018)

\begin{abstract}
The work aimed at reviewing studies on locus of control, depressive symptoms and academic performance of learners generally. It threw more light on the variables of the study for the benefit of the upcoming psychologists, highlighted the state of art in the area and emphasized the benefits of the work so far done. From the review, more research results showed relationship between external locus of control and depression, especially congruent externals. Internal LOC, stable and global attributions for positive events predicted high levels of academic performance. Congruent externality relates positively to depression compared to defensive externality. Stable attribution for negative events were related to high levels of performance in high achieving schools but not in low achieving schools. Significant negative relationship was found between self reported depressive symptoms and college academic performance. Learners with depressive symptoms experience more academic challenges than normal students. It was postulated that having depressive symptoms may not be tied to one's attribution style, but making a realistic attribution. The work recommended among others that depressogenic attribution questionnaire be used in identifying students with depressogenic attribution style for training in realistic appraisal. Also further studies are required to compare the depression status of defensive externals with that of the internals and to compare their academic performance.
\end{abstract}

KEYWORDS: Locus of control, attribution styles, depressive symptoms \& academic performance

\section{INTRODUCTION}

Educators are constantly in search of factors that influence learning with a view to improving teaching and learning outcome. Numerous variables ranging from personal characteristics and environmental factors are known to influence learning and performance. The search on how these variables influence learning and performance is as inexhaustible as ways of improving learning by planned intervention on such variables. Equally, the result of such investigations will continue to be relevant to educators and learners.

This work is aimed at reviewing studies on locus of control, depressive symptoms and academic performance of students generally. It seeks to throw more light on the variables of the study for the benefit of the upcoming Psychologists, highlight the state of art in the area, emphasise the benefits of the work so far done, as well as revealing the gap in literature for further studies. The afore-mentioned variables are all personal characteristics of students.

\section{CONCEPTUAL REVIEW}

Locus of control according to Wikipedia is the degree to which people belief that they have control over the outcome of events in their lives, as opposed to external forces beyond their control. Individuals' "loci" are conceptualized as internal or as external. A person with an internal locus of control (LOC) believes that he or she can

Virginia Nnenna Madu, Department of Educational Psychology, Federal College of Education, Obudu, Nigeria.

(C) 2018 Bachudo Science Co. Ltd. This work is licensed under Creative Commons Attribution 4.0 International license. 
influence events and their outcomes. On the other hand, an external LOC is a belief that one's life can be controlled by outside factors which one cannot influence, or that chance or fate controls one's life (Rotter, 1966). It is expected that an individual whose LOC is internal can positively influence his or her situation more than the other whose LOC is external; who has no control over his situation or believes in luck or fate. It is important to note that one may not be entirely internal or entirely external, but may adjust as the situation demands. However, the central idea is that where an individual has the greater inclination determines the person's locus of control.

Within the dimension of externality we have inbuilt dimensions such as congruent externals and defensive externals. The fact that defensive externals are active and achievement oriented makes them different from congruent externals who are passive and dependent on destiny, luck, fate or chance factor.

Related to locus of control is attribution style. Attribution or explanatory style is a concept attributed to Abrahamson, Seligman \& Teasdale (1976). This concept states that in addition to the concept of internality -externality, a dimension of globality-specificity is also added.

Abrahamson et al believe that how people explain success and failures in their lives relate to whether they attribute these to internal or external factors, short-term or long term factors and factors that affect all situations. Abrahamson's idea of globality-specificity is an elaboration to the concept of LOC as it stresses the causes that could be specific to an individual as well as the causes that are common across individuals. A typical example here is that personal interest in whatever one does is a measure of success, this is specific to individuals. On the other hand, all blind persons cannot see, and this cuts across individuals; indicating an example of globalism. In other words blindness is the same for all individuals, but our interest may vary. These ideas illustrate the fact that explanatory styles can be specific or global. Abrahamson's idea of short term or long term factors could be seen as an elaboration on internality - externality rather than a different dimension of attribution style. Take for instance, interest or lack of it (which is an internal factor) in a given task could be short-lived or long lasting, momentary or enduring.

Weiner (1985) added the dimension of stabilityinstability (and later added a third dimension, controllability), indicating how a cause could be perceived as having been internal to a person, yet beyond the person's control. Altogether, this results in three attribution styles, namely; internal versus external, stable versus unstable and controllable versus uncontrollable. Weiner's idea seems to be a novel factor to the idea of LOC especially the term controllability. A situation (whether internal or external) may seem uncontrollable, but to see it as such is to accept defeat. If a situation demands denial of reality in order to adapt, one has to; this is a dimension of positivity of thought

\section{Depression}

When one goes through a difficult experience, having a feeling of sadness, loneliness or grief is common, and that makes one human. However, sometimes this happens and the person does not bounce back, and that ushers in a different problem; depression. Omeje (2005) defines depression as a mood disorder characterized by inactivity, insomnia early morning awakening, diffused anxiety, poor appetite, and loss of energy, sadness and inability to concentrate. All the definitions of depression by (Hahn \& Payne 1999; youngson,1992; Accardo, Whitman, Beht, fanel, Magenis, Morrow-Carton 2002) point to symptoms of depression. The symptoms include among others, emptiness, hopelessness, unhappiness that is unusually persistent, slow thinking, decrease in pleasure, decreased physical activity, and disruption of eating and sleeping. Forms of depression include major depression, chronic depression, (dysthymia) a milder form of depression that affects millions of people, atypical depression (they may not have the typical symptoms, but may experience symptoms like weight loss/ gain, sleeping too much, feeling anxious). There is also postpartum depression which is common, bipolar depression (manic depression). Manic or bipolar depression is a combination of genetic and non-genetic factors. The mood episode associated with it involves clinical depression or mania (extreme elation and high energy) with periods of normal mood and energy in between episodes.

All forms of depression can impair their 
victim's ability to work and live a normal life. However for the purpose of this discussion, attention is given to major or clinical depression. An individual having major depression is sad most of the time and it affects the person's daily activities. Events in one's life, changes in brain chemistry, and life style can cause depression. The symptoms include, loss of interest or pleasure in your activities, weight loss or gain, trouble getting to sleep or feeling sleepy during the day, feeling restless and agitated, or very sluggish and slowed down physically or mentally, being tired and without energy, feeling worthless or guilty, trouble concentrating or making decisions and thought of suicide. Having five or more of the above symptoms may indicate depression if the symptoms are there on most days for two weeks or more. One of the symptoms must include depressed mood or loss of interest in activities which an individual enjoys before. (Madu, 2012).

There are different theories of depression, such as psychodynamic model, behavioural theories, the helplessness theory, the biological model, cognitive theories. In all these, a combination of cognitive and behavioural theories (CBT) has enjoyed patronage in current research works indicating that both cognitive and behavioural activation result in cognitive change and cognition plays a motivational role in human behaviour (Hopko, Lejuez, Rugiero \& Eifert, (2003) cited in Madu, 2012).

\section{EMPERICAL REVIEW}

\section{Locus of control and depression revisited.} Hirototo (1974) and Capafons (1984) (cited in Jaswal and Dewan, 1997) found externality to be related positively with depression. Endich (1989) (cited in Jaswal and Dewan, (1997) found that depressed students expressed more belief in the importance of chance and powerful others. Lester (1992) and Young (1992) found that internal locus of control scores were negatively related to depression. Jaswal and Dewan (1997) found a negative correlation between depression and internality and positive correlation between depression and powerful others as well as chance. Jaswal and Dewan (1997) found that scores of one hundred and thirty nine (139) girls on IPAT Depression Scale were negatively related to Lewinson's scale for internality and positively related to powerful others and chance locus of control scales. There is also a circular relationship between internality and success and hopelessness in life (Jaswal \& Dewan, 1997). This suggests that internality has its pros and cons. The finding that suggests relationship between internality and hopelessness in life implies that internality relates to depression. An internal's low expectancy for personal control and feelings of powerlessness produce depression. This can occur in a situation where a cause could be internal yet seen as beyond a person's control. In turn, depression leads to inactivity, indecisiveness, hopelessness, such that the individual does not try new experiences not to talk of succeeding in them.

In another study, Zawawi and Hamaideh (2009) carried out a research on depressive symptoms and their correlates with LOC and satisfaction with life among university undergraduates in Hashemite university (HU). A randomized sample of the students $(\mathrm{N}=492)$ completed the multidimensional Health Locus of Control Scale (MHLC), the satisfaction with life Scale (SLS), and the centre for Epidemic Studies Depression Scale (EES_D). Result showed no relationship between externality of LOC (powerful others) and depression, while externality of LOC (Chance) was found to be significantly positively related to depression. A significant negative relationship was found between internality of LOC and depression. Robins (1988) concluded that depression is related to stable-global attributions, whether they are internal or external. The fact that externality of LOC (chance) relates positively to depression lends credence to Robinson's conclusion.

From the studies available to this work, more research results show relationship between external locus of control and depression (Hirototo,1974, Capufons, 1984, Endich, (1989), Jaswan \& Dewan, 1997), and congruent external with depression (Molinari, \& Khanna,2010).

\section{Locus of control and academic performance}

Diane, (2016) conducted a study titled revisiting the relationship between attribution style and academic performance. The work examined the role of specific dimensions of attribution style in predicting subsequent academic performance in a sample of pupils $(\mathrm{N}=979)$ from both low and high achieving schools. Hierarchical regression and moderation analysis indicate that internals, stable and global attributions styles for positive events predict high levels of academic performance. Global attributions for negative events were related to poorer performance 
across all schools. Stable attributions for negative events were related to higher levels of performance in high achieving schools but not in low achieving schools. Higher levels of internality for negative events were associated with higher performance only in low achieving schools,

\section{Depression and academic performance}

It is postulated that depression can be a hindrance to every aspect of a person's life including academic performance. According to the centre for addiction and mental health reported by summers, (2016), clinical depression is defined as a mood disorder caused by many factors including genetic predisposition, personality, stress and brain chemistry. Hysenbegasi, Hass and Rowland (2005) carried a study to determine the relationship between depression and academic performance. In this study there were two groups, the control group that has no diagnosis of depression, and the second group, students with depression who were diagnosed at the on-campus Health Centre. Academic performance was measured by a students ' GPA. Students completed a survey that asked them about their employment, and whether their mental health impacted their ability to attend class, study, and complete assignments. The result of this study indicated that diagnosis of depression was associated with a lower GPA of 0.49 which is equivalent to half a latter grade. In addition depressed students reported missing more classes, tests and assignments compared to the control group. They also dropped more courses and missed more social events.

In another study, Leach, John \& Patrick (2017) examined the association between self reported depressive symptoms and college academic performance. A significant negative relationship was found between depression and academic performance. Furthermore, students presented with moderate levels of depressive symptoms demonstrated low performance within academic environment compared to those with normal and minimal levels of depression.(hppts://www.researchgate.net. publication).

Depression can affect anyone including children. It is one of the few conditions whose symptoms can have a negative impact on almost all aspects of an individual's life. Children with learning disabilities (LD) in particular have been the focus of more than forty years of research on depression. In the early 1970s, there were three reasons why children with LD were believed to be at risk for depression than children without LD:

Children with LD often experience low selfesteem, which is associated with depression. Children who were depressed tended to score lower on academic achievement tests, which is a defining characteristic of LD

Both children with LD and those who were depressed were believed to have some type of neurological disturbance (Maag, cited in Madu, 2012).

Bugged by the question whether children with LD experienced clinical depression at a rate higher than that experienced by the general population, Maag (cited in Madu, 2012) collected every study conducted on depression with LD since 1977 when it became a federal category of disability. He reviewed 15 studies all of which administered a depression inventory to children in the school setting. Three major conclusions were drawn from the review and analysis:

Children with LD had statistically higher depression inventory scores than their non disabled peers, but the magnitude of the difference between the two groups was not great.

Children with LD were at no greater risk for experiencing severe depression than their nondiabled peers.

From the findings above, the fact that children with LD had statistically higher depression score suggest a link between depression and learning disability.

Bonnifacci, Candria, and content (cited in Madu, 2012) conducted a study in which they investigated how specific literacy skills, namely, reading and writing relate to two main dimensions of negative affectivity, i.e. anxiety and depression. Study1 was conducted on third grade children (72), while study two focused on first grade children (43). Two groups of participants were selected because they had been deemed at risk for the development of anxiety or depression and a third (control group) were compared in reading and writing tasks, which included both word and non-word lists. The assessment also included the evaluation of verbal, non verbal and composite IQs. Result indicated that children `at risk' for depression made more spelling errors in dictation of words in comparison to the control 
group. No difference emerged in reading tasks or with reference to the group of children at risk for anxiety. This also shows that there is relationship between depression and learning difficulties.

Ugokwe_Ossai and Ucheagwu (2008) ( (cited in Madu 2012) conducted a study in which they compared the performance of depressives and normal on memory for visual motor test using the Bender Visual-motor Gestalt Test. The participants were fourteen (14) including seven clinically diagnosed depressed patients and seven normal controls. They were marched on gender, age and education. The mean age was 28 years, SD 4.38. The participants were assessed on the following areas: Overly methodical sequence, severe angulation difficulty, severe crossing difficulty and general configuration based on bender gestalt methods of interpretation. Independent t-test was used to analyze the data obtained. Significant difference existed on the four areas of assessment between the depressed group and normals at 0.05 Alfa level.

Hypothesis three which stated that the depressed will show more difficulty in crossing the test figures was accepted. Judging from the mean scores of angulations and crossing, angulations difficulty had higher mean error than the crossing difficulty. Thus recall of angulations appears to pose greater challenge to the depressed group than the crossing difficulty. Angulations difficulty portrays a greater challenge in thought processes and reasoning.

\section{Summary of the Research Findings Revisited} From the research report available to this work, more reports show relationship between external locus of control and depression (HIrototo, 1974; Capufuns 1984; Endich (1989), Jaswal and Dewan, (1997) and precisely congruent externals with depression. The aspect where Jaswal and Dewan (1997) found positive relationship between internality and depression was on hopelessness. If one has administered any depression inventory, one would have realized that a high score on hopelessness correlates highly to scores of other items on depression scales such as Zung or Beck's depression scale. It is either the study was confounded or that the experience of depression does not depend on one's LOC but rather on whether the depression is a primary one or secondary. For instance, secondary or reactive depression which is caused by unfortunate life experiences such as death of a loved one, loss of job can hit anyone; all things being equal the person so affected will bounce back. On the other hand when it is primary depression which is caused by changes in brain chemistry (Madu, 2011), it may not really count if the person is internally controlled or externally controlled. This explanation corroborates Robinson's (1988) conclusion that depression is related to stable global attributions, whether they are internal or external. This is true, a causal attribution to depression that cannot be changed whether internal or external, will keep the individual depressed. Altered brain chemistry remains as such, and cannot but exhibits the associated mood, except something is done to achieve a balance. The remedy does not lie in internality or externality.

From the angle of externality where we have congruent externals and defensive externals, it is found that congruent externality is positively related to depression. This is another score to the idea that the experience of depression may not necessarily be tied to one's LOC orientation, but having a realistic appraisal of situations, knowing when to look inward or outward. Where this realistic appraisal is lacking, a congruent external might be mislead into swallowing hook line and sinker the influence of the powerful others.

\section{Implications of the review to learners}

From the forgone discussions, it can be inferred that making a stable- internal- global attributions and being a congruent external can be depressogenic. Whereas an internal, stable and global causal interpretation of negative events may predispose someone to depression, it is important to find out whether something can be done about the situation to remedy it. This is important in view of the fact that depression is a negative affect that does nobody any favour.

It is not really the attribution styles that produce depression in the real sense, but whether the attribution one makes is realistic or not. In view of this, individuals should make realistic appraisal of their world (events, problems and behaviour). A student who fails an examination because she did not study hard, but attributes the cause to her lecturer has made a faulty appraisal, and her situation cannot change except she tells herself the truth.

Since greater research work showed that students with depressive tendencies had more 
academic problems than the normal and those with minimal depression, it implies that effort should be made to guide students in reducing their depression symptoms.

\section{RECOMMENDATIONS}

1. Depressogenic attribution questionnaire can be used in identifying students attribution styles. This will help to identify students with depressogenic attribution styles for counselling in making realistic appraisal of attribution.

2. Further studies are required to compare the depression status of the defensive externals and individuals with internal LOC and the influence on academic performance.

3. Further studies are also required to explain why stable attribution for negative events relates positively to higher level of performance in higher achieving students only, while higher internality relates positively to higher performance only in low achieving schools.

4. Life skill training is recommended as a way of helping students in reducing their depression symptoms.

\section{REFERENCES}

Abrahamson, L. Y., Seligman, M. E. P and Teasdale, J. D., 1976. Learned helplessness in Humans: critique and reformation. Journal of abnormal psychology. 87, (1): 49-74.

Diane, M., 2016. Revisiting the relationship between attributional style and academic performance. Journal of Applied Social psychology 46(3), 192-200. Retrieved on November, 22, 2017 from https://doi,org/10.11111/asp.12356

Hirototo, O. S., 1974. Learned helplessness and locus of control. Journal of experimental Psychology.102, 187-193.

Hysenbegasi, A., Hass, S. C and Rowland, C. R., 2005. The impact of depression on Academic productivity of university students. Journal of Mental health, Policy And Economics 8(3), 45
Jaswal, J and Dewan, A., 1997. Relationship between locus of control and depression. journal of personality and clinical studies, 13(1-2), 25-27.

Leach, V. M., John, B and Patrick, L. J., 2017. Association between self reported depressive symptomatology and college academic performance. College students journal 43, (2): 325-334.

Lester, D., 1992. The emotional profile index and locus of control. Perceptual and motor Skills.75,530.

Madu, V. N., 2011. Counselling students with depressive tendencies for better educational and personal-social adjustment: the cognitive restructuring approach. Global Journal of Educational Research, 10, (1): 29-33.

Madu, V. N., 2012. Effect of cognitive restructuring and assertive therapies on the reduction of depressive tendencies among colleges of education students. Unpublished doctoral dissertation, Nnamdi Azikiwe University, Awka.

Molinari, V and Khanna, P., 2010. Locus of control and its relationship to anxiety and depression. Journal of Personality Assessment, 314-319. Retrieved July, 25 fromhttps://doi,org/10.1207/s15327752ip a4503...14

Omeje, O., 2005. Physiological psychology $\left(2^{\text {nd }}\right.$ ed). Enugu. Glanic Ventures.

Rotter, J. B., 1985. Generalized expectancies for internal versus external Control of reinforcement. Psychological monographs. 90(609) doi: 101037/101037/h0092976

Summer, C., 2016. The relationship between depression and academic performance. Psychology, Neuroscience and Behaviour, McMaster University.

Weiner, B., 1985. An attributional theory of achievement motivation Retrieved on January 17, 2018. From https:// en Wikipedia. Org.wiki>Benard........ on January 17, 2018. 
Young, T. J., 1972. Locus of control and self reported psychopathology among Native Americans. Social behaviour and personality, 20, 235-236.
Zawawi, A. L. and Hamaideh, S. A. (2009). Depressive symptoms and their correlate with locus of control and satisfaction with life among Jordanian college students. Europe's Journal of Psychology, 5(4), 71-103. 